\title{
Non closure of parietal peritoneum at cesarean section and adhesion formation
}

\author{
Anjali Choudhary*, Neeta Bansal
}

Department of Obstetrics and Gynecology, SGRRIM \& HS, Patel Nagar, Dehradun, Uttarakhand-248001, India

Received: 4 August 2013

Accepted: 17 August 2013

\section{*Correspondence:}

Dr. Anjali Choudhary,

E-mail: anjusun@yahoo.com

(C) 2013 Choudhary A et al. This is an open-access article distributed under the terms of the Creative Commons Attribution Non-Commercial License, which permits unrestricted non-commercial use, distribution, and reproduction in any medium, provided the original work is properly cited.

\begin{abstract}
Background: Cesarean section is the most commonly performed surgery worldwide. Recent times have seen rising trends in c-section rates, for a variety of reasons. Although the basic procedure remains same, some new techniques have been adopted like not closing the visceral or the parietal peritoneum. A large number of studies on merits and demerits of these practices have been published, generating even larger debates. Objective of this effort is to evaluate studies on either side of the argument and cite our experiences.

Methods: Repeat cesarean sections were evaluated for adhesion related procedural problems in both peritoneal closure and non closure in primary cesareans.

Results: Dense adhesions were observed in cases where peritoneal closure was not done in previous surgery and there were fewer or less dense adhesion cases where routine closure of parietal peritoneum was practiced.

Conclusion: Routine closure of parietal peritoneum in cesarean sections is recommended to reduce adhesion related morbidity and difficult subsequent surgery.
\end{abstract}

Keywords: Cesarean-section, Adhesions, Parietal peritoneum closure, Peritoneal non closure

\section{INTRODUCTION}

Cesarean section is the most widely performed surgery. There is an increasing trend in the incidence of c-sections worldwide. Although the basic procedure remains same, some newer techniques are adapted like not closing the visceral or the parietal peritoneum. Large number of studies has been published on merits and demerits of this practice generating even larger debates. Whether the parietal peritoneum should be closed at cesarean section or not, has generated as much controversy as no other topic in recent times, amongst obstetricians. The arguments for either side are so convincing that no one side is ready to come on an even platform. The question still looms large, almost as challenging as the proverbial Shakespearian dilemma-to close or not to close? Through our basic knowledge and training of surgical skills we know that all that is incised during surgery should be stitched back so as to restore the anatomy back to as normal as possible. Also a fact as quoted by Wallter and
Isreal, the healing of the peritoneum and other serosal surfaces happens by metaplasia of the underlying connective tissue. ${ }^{1}$ Granted, that peritoneum regenerates within eight days as some the studies advocating non closure of peritoneum would argue, but during that time it will stick to everything in between and form dense adhesions if peritoneum is left unsutured. It would make future surgeries difficult and time consuming and cause extra morbidity to the patient due to chronic pain, infertility, dysparaunia, intestinal obstruction and hernia. ${ }^{7}$ The intent is not to 'regenerate' the peritoneum by closing it but to keep the intra-abdominal contents inside the abdomen where they belong. Peritoneal closure is a way to put an inter-phase between the abdominal wall and abdominal contents, because peritoneum is there for a reason. This article is an attempt to review and compare the available literature on either side of the controversy, tally it with our experiences and put forward our opinions and recommendations. Peritoneal healing after cesarean section is slightly different than other laparotomies for a 
simple reason that there is a 16 to 18 weeks size puerperal uterus in the midline pushing the omentum and intestines through the incision in the peritoneum. If parietal peritoneum is left unsutured and the peritoneum regenerates by eighth post operative day, the adhesions would form, binding the uterus to the anterior abdominal wall, omentum and even intestine. Parietal peritoneal closure in primary c-sections is associated with fewer and less dense adhesions. ${ }^{3}$

\section{METHODS}

A total of forty eight cases of repeat sections were prospectively followed. The first group (Group C) consisted of twenty four cases where peritoneal closure was done in previous surgery. The second group (Group NC) also had twenty four cases where the peritoneum was left unsutured in previous surgery.

Using a questionnaire, the data of all forty eight cases pertaining to their experience of previous surgery was assessed and recorded regarding hospital stay, postoperative pain, wound complication etc. During the repeat surgery the findings were evaluated in both groups for presence of adhesion, their nature and severity, length of surgery, degree of procedural difficulty and post operative morbidity. The adhesions were graded in four categories namely,
1. Grade 0: no adhesion,

2. Grade 1: mild flimsy adhesion,

3. Grade 2: moderate omento-facial adhesions,

4. Grade 3: severe adhesions with bladder, bowel attachments.

\section{RESULTS}

In both groups post primary section, there were no significant differences in immediate post operative morbidity, like post operative pain, requirement of analgesics, febrile episodes, wound problems and hospital stay. More significant observations were the peroperative findings in repeat cesarean. In the patients of Group NC where parietal peritoneum was left unsutured during previous surgery, dense adhesions were found during laparotomy, access to the peritoneal cavity was difficult and time consuming. Adhesiolysis was needed to reveal the uterus, resulting in longer incision delivery interval and surgical time. In Group NC, approximately $65 \%$ patients had moderate to severe adhesions as compared to approximately $8 \%$ in Group C. The mean surgical time was 67 minutes in Group NC and 46.2 minutes in Group C.

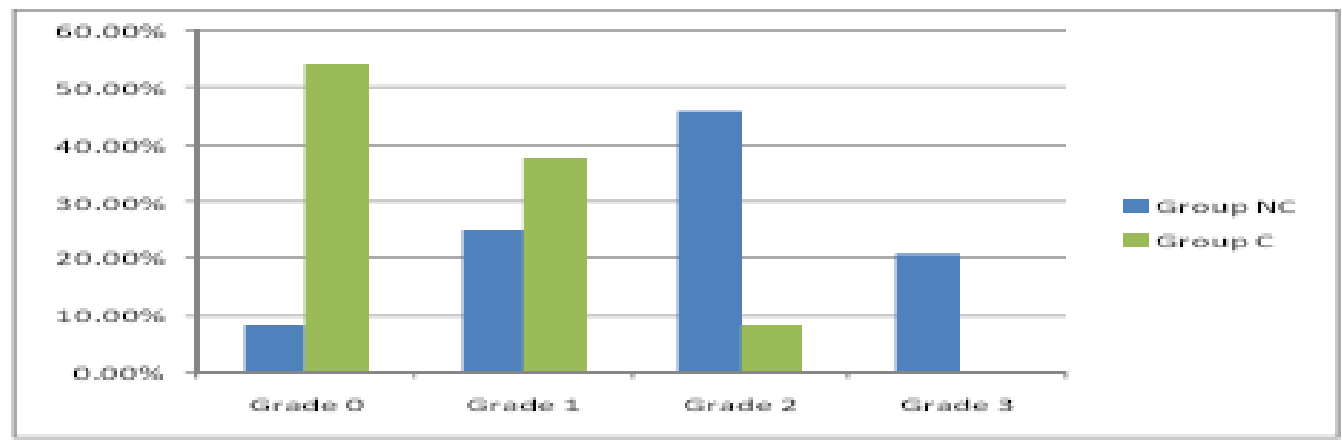

Figure 1: Intra-operative findings (in repeat sections).

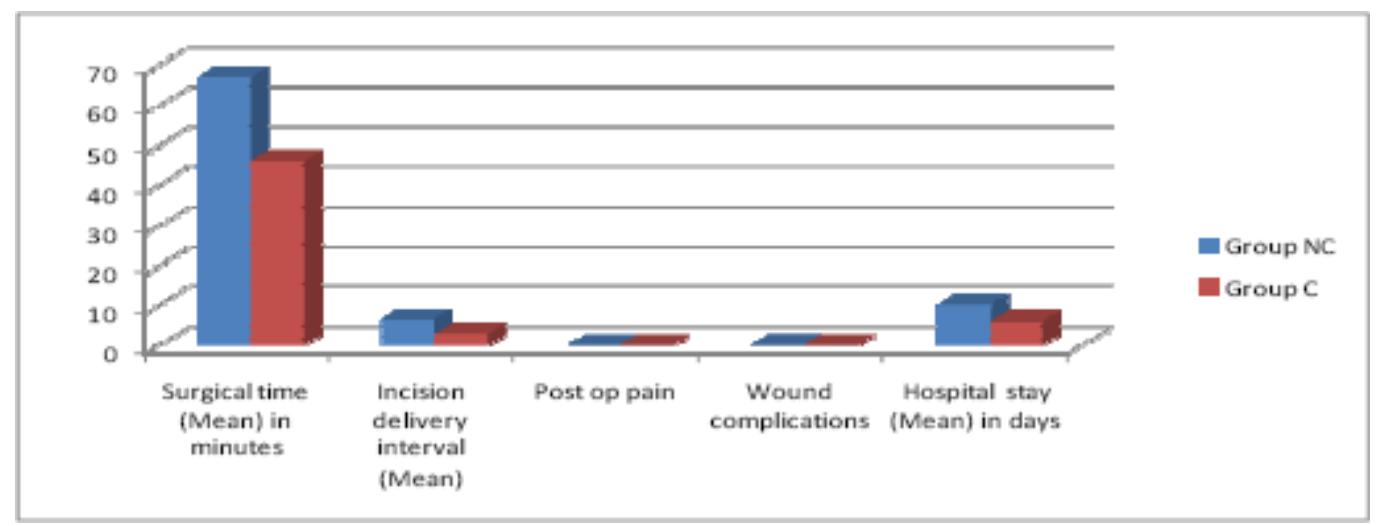

Figure 2: Comparative variables (in repeat sections). 
In some cases anterior abdominal wall was stuck to the anterior uterine wall in the midline. Omentum was found to be covering the uterus. In many instances rectus muscle was incorporated in the uterine wall. Some patients even had small bowel loops adherent to anterior abdominal wall, making opening of abdomen difficult and risky. In certain cases extra peritoneal cesarean was done to shorten incision delivery interval. Fallopian tubes were inaccessible for ligation. In few instances blood loss was more than average because of extensive adhesions.

Since there were no definite peritoneal edges, closure of peritoneum was difficult and rectus sheath was closed directly without closing peritoneum. In the cases of Group C, where closure of parietal peritoneum was routinely practiced, second surgery was easier, faster, cleaner with few and flimsy adhesions. Mean surgical time and incision delivery interval was shorter.

Figure 2 shows that surgical time and incision delivery interval is increased in group $\mathrm{NC}$, but the post operative pain and wound complications remain similar in both groups.

Table 1: Intra-operative findings (in repeat sections).

\begin{tabular}{|lll|ll|}
\hline & \multicolumn{2}{l}{ Group NC } & \multicolumn{2}{l|}{ Group C } \\
\hline Adhesions & Count & Percentage & Count & Percentage \\
\hline Grade 0 & 2 & 08.33 & 13 & 54.17 \\
\hline Grade 1 & 6 & 25.00 & 9 & 37.50 \\
\hline Grade 2 & 11 & 45.83 & 2 & 08.33 \\
\hline Grade 3 & 5 & 20.83 & 0 & 00.00 \\
\hline
\end{tabular}

Table 2: Comparative variables (in repeat sections).

\begin{tabular}{|lll|}
\hline Parameter & $\begin{array}{l}\text { Group } \\
\text { NC }\end{array}$ & $\begin{array}{l}\text { Group } \\
\text { C }\end{array}$ \\
\hline Surgical time (Mean) in Minutes & 67 & 46.2 \\
\hline $\begin{array}{l}\text { Incision delivery interval (Mean) } \\
\text { in Minutes }\end{array}$ & 6.5 & 2.9 \\
\hline Post op pain & $6 \%$ & $3.4 \%$ \\
\hline Wound complications & $8 \%$ & $1.2 \%$ \\
\hline Hospital stay (Mean) in Days & 10 & 6 \\
\hline
\end{tabular}

\section{DISCUSSION}

Non closure of the parietal peritoneum in cesarean sections will definitely reduce the surgical time by five to six minutes which many of the studies advocating nonclosure endorse. ${ }^{2,3}$ A study conducted in army hospital in Pakistan comparing closure versus no closure of peritoneum concluded that peritoneal non-closure was recommended as it reduces the operating time, anesthesia dose, quicker recovery and shorter hospital stays. ${ }^{8}$
However, that is not a great advantage, especially not at the cost of adhesion formation and a problematic next surgery as observed in our study. In repeat surgeries done on patients where peritoneal was left unsutured in previous surgery the operating time was longer, blood loss more and postoperative periods were turbulent with longer hospital stays. Most of the studies advocating non closure of peritoneum, have compared immediate post operative morbidity in terms of postoperative pain, febrile episodes, hospital stay etc in closure and non-closure group and have not considered long term consequences like adhesion related morbidity and procedural difficulties in next surgery when required. ${ }^{3,4}$ In a double blind randomized trial conducted by $\mathrm{B}$. Chanrachakul S. Hamontri, Y. Herabutya to compare the intensity of postcesarean pain between closure and non closure of peritoneum in the women,it was concluded that there was no difference in postoperative pain in both groups in repeat cesarean patients. ${ }^{9}$ Since there is not much difference in post operative pain, hospital stay and wound problems in closure and non closure group, why not close the peritoneum? Surgeries were cumbersome in patients who had non closure of peritoneum in previous surgery, due to dense omento-facial adhesions. Separation of these adhesions to access lower uterine segment ensued profuse bleeding. Sometimes bowel loops were stuck in the bands of adhesion. There was unacceptable blood loss and risk of injuries to bladder and bowel during dissection of adhesions.

Cheong Y C, et al in their review of 14 studies observed that Non-closure of the peritoneum during Cesarean Section resulted in a significantly increased incidence of adhesion formation. ${ }^{5}$ In another study by Zareian $\mathrm{Z}$ and Zareian $\mathrm{P}$ where a prospective randomized trial was performed on 45 patients. The results revealed that the closure of the peritoneum increases the operating time, but may decrease the risk of adhesions and, suggested that, during cesarean section, suture of the peritoneum may be a better option than leaving it unsutured. ${ }^{6}$ This agrees with our observation for cases of repeat surgery on patients who had closure of the parietal peritoneum in prior surgery, the operation was easier and with less or only flimsy adhesions. The peritoneal cavity was almost as clean as it would be in a primary surgery, the blood loss was average, opening and closing of the abdomen was faster. These patients had uneventful post-operative periods and short hospital stay. The study conducted by Lyell DJ, Caughey AB, Hu E, Daniels K further endorses our observations. ${ }^{10}$ They found that parietal peritoneal closure at primary cesarean delivery was 5 -fold protective against all adhesions and 3-fold protective against dense adhesions. The conclusion of the study coincides with our findings that the practice of non closure of the parietal peritoneum at cesarean delivery should be questioned. ${ }^{10}$

\section{CONCLUSION}

In cases of repeat surgeries, adhesion related problems are more if the parietal peritoneum is left unsutured in a 
prior surgery. Surgeries are faster cleaner where peritoneum was sutured. Routine closure of parietal peritoneum in cesarean sections is recommended to reduce adhesion related morbidity and difficult subsequent surgery.

\section{REFERENCES}

1. Wallter JB, Isreal MS. Healing of specialized tissues. Text book of pathology, chapter 10, pages 135-136.

2. diZerega GS, Campeau JD. Peritoneal repair and post-surgical adhesion formation. Hum Reprod Update. 2001;7:547-55.

3. Practice Committee of American Society for Reproductive Medicine in collaboration with Society of Reproductive Surgeons. Pathogenesis, consequences, and control of peritoneal adhesions in gynecologic surgery. Fertil Steril. 2008 Nov;90(5 Suppl):S144-9.

4. Cheong YC, Laird SM, Li TC, Shelton JB, Ledger WL, Cooke ID. Peritoneal healing and adhesion formation and reformation. Human Reproduction 2001;7:556-66.

5. Bigatti G, Boeckx W, Gruft L, Segers N, Brosens I. Experimental model for neoangiogenesis in adhesion formation. Hum Reprod 1995;10:2290-4.
6. Cheong YC, Laird SM, Li TC, Shelton JB, Ledger WL, Cooke ID. To close or not to close? A systematic review and a meta-analysis of peritoneal non-closure and adhesion formation after caesarean section. Eur J Obstet Gynecol Reprod Biol 2009;147:3-8.

7. Zareian Z, Zareian P. Non-closure versus closure of peritoneum during cesarean section: a randomized study. Eur J Obstet Gynecol Reprod Biol. 2006 SepOct; 128(1-2):267-9.

8. Shahzia Shakeel, Azra Batool, Nilofer Mustafa. Peritoneal non- closure at caesarean section- A study of short term post-operative morbidity. Pakistan Armed Forces Medical journal 2008;30:9648.

9. Chanrachakul B, Hamontri S, Herabutya Y. A randomized comparison of post cesarean pain between closure and nonclosure of peritoneum. Eur J Obstet Gynecol Reprod Biol 2002;101:31-5.

10. Lyell DJ, Chaughey AB, Hu E, Daniels K. Peritoneal closure at primary cesarean delivery and adhesions. Obstet Gynecol. 2005;106(2):275-80.

DOI: 10.5455/2320-1770.ijrcog20130929

Cite this article as: Choudhary A, Bansal N. Non closure of parietal peritoneum at cesarean section and adhesion formation. Int J Reprod Contracept Obstet Gynecol 2013;2:406-9. 